\title{
Endometrial sampling devices for early diagnosis of endometrial lesions
}

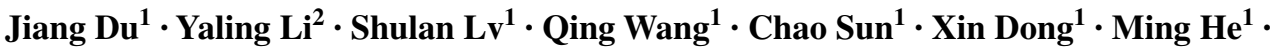 \\ Qurat Ulain $^{1} \cdot$ Yongxing Yuan $^{1} \cdot$ Xiaoqian Tuo $^{1} \cdot$ Nasra Batchu $^{1} \cdot$ Qing Song $^{1,3,4}$. \\ Qiling $\mathbf{L i}^{1,4}$
}

Received: 2 April 2016 / Accepted: 3 August 2016 / Published online: 11 August 2016

(C) The Author(s) 2016. This article is published with open access at Springerlink.com

\begin{abstract}
Purpose Endometrial carcinoma is the most common gynecologic malignancy in both developed and some developing countries. Unlike cervical cancer, for which there is routine screening, only patients symptomatic for endometrial carcinoma typically seek medical help for its diagnosis and treatment. Dilatation and curettage (D\&C) has been the standard procedure for evaluating suspicious endometrial lesions. The discomfort and injury caused by the D\&C procedure, however, restrict its use as a screening method for early diagnosis of endometrial lesions. High-risk endometrial cancer patients would benefit from an effective and low-cost screening test. In recent years, several endometrial devices have been developed and proposed as screening tools.

Methods We have reviewed and evaluated the literature relating to the endometrial sampling devices in clinical use or clinical trials, with the goal of comparing devices and identifying the most appropriate ones for screening
\end{abstract}

Jiang Du, Yaling Li and Shulan Lv have contributed equally to this work.

Qiling Li

liqiling@mail.xjtu.edu.cn

1 Department of Obstetrics and Gynecology, First Affiliated Hospital, Xi' an Jiaotong University, Xi' an 710061, Shaanxi, China

2 Gongzhuling Health Workers High School, Gongzhuling 136100, Jilin, China

3 Cardiovascular Research Institute, Morehouse School of Medicine, Atlanta, GA 30310, USA

4 Center of Big Data and Bioinformatics, First Affiliated Hospital, Xi' an Jiaotong University, Xi' an 710061, Shaanxi, China for endometrial lesions. Eligible literature was identified from systematic PubMed searches, and the relevant data were extracted. Comments, letters, unpublished data, conference proceedings, and case reports were excluded from our search. Seventy-four articles on endometrial sampling devices were obtained for this review.

Results The main screening devices for endometrial carcinoma are aspiration devices (such as the Vabra aspirator), Pipelle, Tao Brush, and SAP-1 device. Among these devices, the Tao Brush is the most promising endometrial sampler for screening for endometrial lesions. However, its sampling insufficiency, cost, and unsuccessful insertion rate (20\% in nulliparous and $8 \%$ in parous women) are problematic.

Conclusions A more accurate and low-cost endometrial sampler, with improved specimen sufficiency and higher sensitivity for endometrial lesions, needs tobe developed and clinically verified.

Keywords Endometrial lesions · Aspiration · Biopsy · Brush $\cdot$ Screening

\section{Abbreviation \\ D\&C Dilatation and curettage}

\section{Introduction}

Endometrial carcinoma is the most common gynecologic malignancy in western countries (Bray et al. 2005; Siegel et al. 2013), as well as in developed cities in China such as Beijing, Shanghai, and Zhongshan. It has supplanted cervical cancer as the leading gynecological malignancy (Siegel et al. 2013, 2014; Gao et al. 2015). With the increasing morbidity and mortality of endometrial carcinoma around the world, 
there would be social and economic benefit from a screening tool that could be used for early detection, leading to earlier treatment of endometrial carcinoma. Unfortunately, unlike cervical cancer, no effective and low-cost screening program for early detection of endometrial carcinoma has been established at this time (Broso 1995). Curetting is still the standard procedure for evaluating endometrial lesions such as carcinoma and hyperplasia, but this procedure has several deficiencies. Besides of its tendency to cause pain and injury, as well as its cost (Tabata et al. 2001), curetting can only evaluate less than half of the uterine cavity in approximately $60 \%$ of dilatation and curettage (D\&C) procedures, which can result in false-negative diagnoses (Kipp et al. 2008). Therefore, there is an urgent need for alternative devices which can be used for early detection of endometrial lesions, especially carcinoma and its precursors. Since the 1970s, several uterine sampling devices which show relatively high sensitivity and specificity for early diagnosis of endometrial lesions have been developed for screening for endometrial lesions (Longacre et al. 1995; Bistoletti and Hjerpe 1993; Vuopala et al. 1989; Tajima et al. 1998; vanHoeven et al. 1996). This review provides an overview of available endometrial devices for sampling and early diagnosis of endometrial lesions, critically evaluates the advantages and deficits of these samplers, and suggests considerations for future development of such devices.

\section{Methods}

A literature search from January 1, 1990 to July 10, 2015 was performed using PubMed for articles about endometrial devices. The keywords used included "aspiration technology for endometrium," "endometrial aspiration device," "Pipelle biopsy," "brush for endometrium," "brush for endometrial carcinoma," "Tao Brush", and "SAP-1 device." Searches were restricted to human studies and English language publications, and other articles concerning endometrial pathology were excluded. Seventy-four relevant articles on endometrial sampling devices were obtained for our review. Citation lists of retrieved articles were checked to ensure sensitivity of the search methods.

\section{Results}

The main screening devices for endometrial carcinoma are aspiration devices, Pipelle, Tao Brush, and SAP-1 brush sampler, as outlined in Fig. 1.

\section{Aspiration devices}

Aspiration technology was described by Bela Lorincz, in 1934, as a method with few complications that could be used

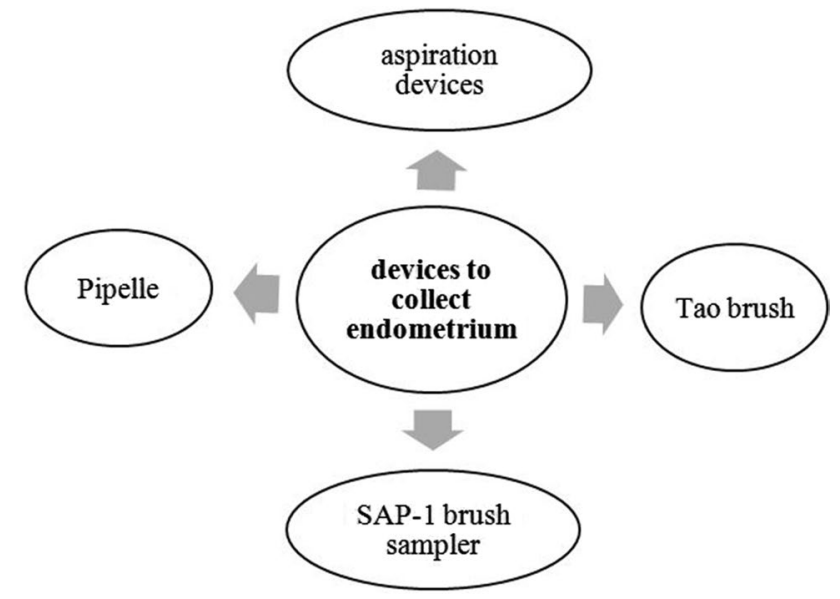

Fig. 1 Ways to collect endometrium

in an outpatient setting. More recently, aspiration technology has been shown to be a safe, simple, and reliable technique for screening for endometrial lesions (Hemalatha et al. 2006; Kaur et al. 2014; Kawana et al. 2005; Roberts et al. 1994; Rosler et al. 1991; Morse et al. 1982; Niklasson et al. 1981; Poppendiek and Bayer 1981; Masukawa 1981; Smith et al. 1980). Among all of the aspiration devices, the Vabra aspirator is most commonly used for clinical trials to evaluate endometrial lesions. The Vabra aspirator is a metal cannula with a length of $24 \mathrm{~cm}$ and an external diameter of $3 \mathrm{~mm}$. At the inner side of the curved ending, it has an aperture of $1.5 \times 16 \mathrm{~mm}$. The cannula is connected to a plastic receptacle, which contains a sieve, also of plastic material, to retain the fragments of tissue. After insertion of the cannula into the uterine cavity, the pump is switched on. The two proximal openings in the cannula are covered by an index finger to create negative pressure, while holding the plastic receptacle of the Vabra aspirator. As a result, the uterus is emptied by suction, and then the cannula is withdrawn from the uterus briefly. The procedure is then repeated several times to make sure that the whole interior surface of the uterus is sampled (Lubbers 1977).

In one study, the specimens obtained by aspiration were adequate for cytology in $93 \%$ of cases, among 150 patients (Tripathy and Mahanty 1990). In a symptomatic group of 100 women, a specificity of $88.7 \%$ and a sensitivity of $88.2 \%$ were found, in comparison to histological diagnosis, with only $2 \%$ of the results being false negative. The use of aspiration in endometrial cell sampling also seems to be promising as a screening tool in asymptomatic women (Rosler et al. 1991). In an article by Rodriguez et al., twenty-five patients who were scheduled for hysterectomy were randomly assigned to undergo preoperative endometrial biopsy by Pipelle device (discussed below) (12 patients) or Vabra aspiration (13 patients). The Vabra aspirator was shown to be statistically superior in sampling 
Table 1 Review of the literature on Pipelle biopsy for diagnosis of endometrial lesions

\begin{tabular}{|c|c|c|c|c|c|c|}
\hline Year & References & Cases & $\begin{array}{l}\text { Curettage or } \\
\text { hysterectomy }\end{array}$ & Pipelle & $\begin{array}{l}\text { Specimen } \\
\text { satisfaction (\%) }\end{array}$ & $\begin{array}{l}\text { Pathological } \\
\text { accuracy (\%) }\end{array}$ \\
\hline 2015 & Sanam and Majid (2015) & 130 & 130 & 130 & 88.0 & 94.0 \\
\hline 2014 & Rauf et al. (2014) & 203 & 101 & 102 & 98 & - \\
\hline 2014 & Gungorduk et al. (2014) & 267 & 189 & 78 & - & 62.0 \\
\hline 2013 & Leng et al. (2013) & 200 & 200 & 200 & 93.0 & 85.0 \\
\hline 2012 & Kazandi et al. (2012) & 82 & 82 & 82 & 93.0 & 66.0 \\
\hline 2008 & Fakhar et al. (2008) & 100 & 100 & 100 & 98.0 & 94.0 \\
\hline 2003 & Machado et al. (2003) & 1535 & 168 & 1535 & 73.9 & 96.9 \\
\hline 1995 & Guido et al. (1995) & 65 & 65 & 65 & 97.0 & 83.0 \\
\hline 1994 & Zorlu et al. (1994) & 26 & 26 & 26 & 100 & 95.0 \\
\hline 1994 & Ben-baruch et al. (1994) & 269 & 97 & 172 & 90.6 & 95.5 \\
\hline
\end{tabular}

the percentage of endometrial surface, the mean number of endometrial surfaces, and the mean number of endometrial quadrants (Rodriguez et al. 1993).

Though aspiration sampling could reduce costs compared with curettage, one limitation is that it may be perceived as a procedure for abortion-related treatment in some countries where abortion is illegal (Foster-Rosales et al. 2003). The procedure success rate to collect endometrium in the Vabra was shown to be less than the Pipelle ( $88.7 \%$ vs. $98.7, P=0.02$ ). Cost-benefit analysis by Naim et al. revealed a higher average cost per patient in the Vabra group compared to the Pipelle group (Naim et al. 2007). Additional limitations of the Vabra aspirator were that in some cases it did not result in adequate endometrium being obtained and did not allow diagnosis of other uterine pathologies, such as endometrial polyps and uterine myoma (Leonardi et al. 1993). As Goldberg et al. reported, the Vabra aspirator could not be inserted in five out of 40 patients because of cervical stenosis (Goldberg et al. 1982). Kaunitz et al. compared the performance of the Pipelle to the Vabra aspirator in 50 patients, and found that the Pipelle obtained more tissue than the Vabra in 28 patients $(50 \%)$, and was noted by the clinician to cause less pain in 50 patients $(89 \%)$. Forty-seven patients $(84 \%)$ stated that biopsy with Pipelle was less painful than with Vabra aspirator (Kaunitz et al. 1988; Wu et al. 2000).

Other aspirators such as Accurette (Kriseman 1982), Isaacs cell sampler (Polson et al. 1984), manual vacuum aspiration (Foster-Rosales et al. 2003; Kitiyodom 2015), and corkscrew (Sierecki et al. 2008) have also been used for evaluating endometrial lesions, but they have not been extensively applied in the clinic because of a lack of supporting data.

\section{Pipelle}

Introduced by Cornier in 1984 (Eddowes et al. 1990), the Pipelle is the most studied biopsy device in the literature (Eddowes et al. 1990; Youssif and Mcmillan 1995; Eddowes et al. 1990; Leng et al. 2013; Fakhar et al. 2008; Elsandabesee and Greenwood 2005; Machado et al. 2003; Dijkhuizen et al. 2000; Sundsbak and Jebsen 1994; Zorlu et al. 1994; Sanam and Majid 2015; Ben-baruch et al. 1994; Leclair et al. 2011). The Pipelle device is $23.5 \mathrm{~mm}$ in length, with a polypropylene sheath with an outer diameter of $3.1 \mathrm{~mm}$. Suction is created along a negative pressure gradient when the inner plunger is withdrawn (Leclair et al. 2011). The Pipelle endometrial sampler can be used without cervical dilatation in the outpatient department and causes minimum discomfort.

As compared to traditional D\&C, Pipelle sampling is a less time-consuming procedure (Sanam and Majid 2015; Rauf et al. 2014). The specimen satisfaction rate of Pipelle, according to articles from 1994 to 2015, ranged from 73.9 to $100 \%$. Meanwhile, pathological accuracy was 62.0 to $96.9 \%$ for endometrial lesions (Leng et al. 2013; Fakhar et al. 2008; Machado et al. 2003; Zorlu et al. 1994; Sanam and Majid 2015; Rauf et al. 2014; Gungorduk et al. 2014; Kazandi et al. 2012; Guido et al. 1995; Ben-Baruch et al. 1994), with greater acceptability for patients than D\&C (Table 1).

Although adequate tissue for histopathologic examination was obtained in slightly fewer cases than for D\&C ( 98 vs. $100 \%$ ), the acceptability of the Pipelle was $98 \%$ and of the D\&C was $34 \%$ in a study by Raufet al. (Rauf et al. 2014). In a meta-analysis by Dijkhuizen et al. the results of Pipelle sampling were compared with other surgeries such as D\&C, hysteroscopy, or hysterectomy between 1996 and 1999, and the conclusion was that the Pipelle was the best device for detecting endometrial lesions in both postmenopausal and premenopausal women, with detection rates of 99.6 and $91 \%$, respectively (Fakhar et al. 2008). In the study of Demirkiran et al., 673 patients were evaluated by Pipelle biopsy from October 2007 to November 2009. Compared with pathological examination after hysterectomy, the histological 
concordance rate was only $67 \%$ for Pipelle biopsy and $70 \%$ for D\&C. The sensitivity of Pipelle biopsy and D\&C was both $99 \%$, but Pipelle was easier to perform than D\&C for surgeons (Demirkiran et al. 2012). Gungorduk et al. evaluated patients undergoing hysterectomy for various indications via Pipelle endometrial biopsy or D\&C from 2009 to 2011. A total of 267 women were included, with 78 women enrolled in the Pipelle group and 189 in the D\&C group. The concordance rate with histological diagnosis between Pipelle biopsy and hysterectomy was $62 \%$, and between D\&C and hysterectomy was $67 \%$. Pipelle biopsy and D\&C were equally successful for diagnosing endometrial lesions (Gungorduk et al. 2014). Abdelazim et al. compared the diagnostic sensitivity of Pipelle with D\&C in patients undergoing abnormal uterine bleeding; the rate of obtaining adequate endometrium for histological diagnosis was $100 \%$ for D\&C and $97.9 \%$ for the Pipelle group. The sensitivity of Pipelle biopsy was $100 \%$ for endometrial hyperplasia, endometrial carcinoma, proliferative, and secretory endometrium, whereas the sensitivity for diagnosing endometritis was $88.9 \%$ (Abdelazim et al. 2013). Pipelle was also shown to be useful in obtaining endometrial tissue for hormonal evaluation (Check et al. 1989), as well as in patients treated with progestin for endometrial hyperplasia (Kim et al. 2015).

However, other reports describe the limitations of the Pipelle biopsy. It may be less efficient than other methods as a screening tool, because only a small proportion of the endometrial surface can be sampled (Batool et al. 1994), and furthermore, the Pipelle biopsy has limited ability to identify focal lesions (Kazandi et al. 2012). In Tanriverdi et al.'s report, 13 patients in the D\&C group and 29 patients in the Pipelle group had insufficient tissue, among 127 patients. The authors concluded that Pipelle sampling should be reserved for those patients with only a minimal risk for endometrial carcinoma, hyperplasia, and polyps (Tanriverdi et al. 2004). The sensitivity and specificity of Pipelle in endometrial samplings were compared to fractional curettage in postmenopausal patients and found to be 87.5 and $100 \%$, respectively. One out of three cases of endometrial adenocarcinoma could not be diagnosed by Pipelle (Bunyavejchevin et al. 2001). Tumors localized to a polyp or a small area of endometrium may go undetected with Pipelle (Guido et al. 1995), and the Pipelle procedure is almost eight times as costly as D\&C (Rauf et al. 2014). The Pipelle also showed its limitations for diagnosing endometrial polyps, with a sensitivity of only $60 \%$ in the report by Abdelazim et al. (2013).

\section{Tao Brush}

The Tao Brush was introduced in 1993 and approved by the Food and Drug Administration for general medical use (Tao 1997) (Fig. 2a). To begin collection of endometrial cells, the
A

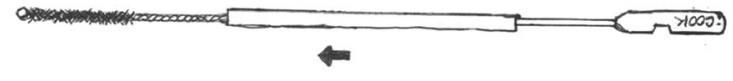

B

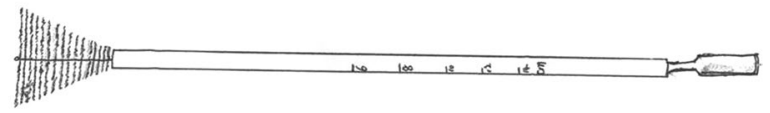

C

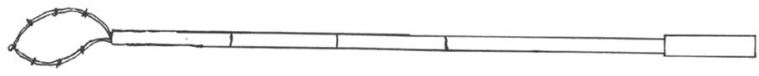

Fig. 2 Three types of brushes for endometrial cytology. a Tao Brush; b Li Brush; c SAP-1 endometrial sampler

sheath is pulled back, and then the brush is inserted at the level of the fundus through the cervical canal. The $3.5-\mathrm{cm}$ brush is then rotated $360^{\circ} 3-5$ times to collect endometrial cells. The outer sheath is then pushed back to the tip, and the device is removed from the uterine cavity. The brush is cut off and immersed into cell preservation liquids and sent for cytological assessment and diagnosis (Kipp et al. 2008).

The Tao Brush can be used in an outpatient setting, without the need for anesthetic, as it is simple to use and appears to be well tolerated by women. Specimen satisfaction with the Tao Brush, according to articles from 1997 to 2003, was 89.9 to $100 \%$, while the pathological accuracy was 91.0 to $96.0 \%$ (Wu et al. 2000, 2003 Maksem et al. 1997; Del Priore et al. 2001) (Table 2).

There was less specimen insufficiency for diagnosis with the Tao Brush $(2 \%)$ than with the Pipelle (12\%). Additionally, the Tao Brush was significantly less painful than Pipelle $(P<0.01)$ (Yang and Wan 2000). In Del Priore et al.'s study, the Tao Brush had $95.5 \%$ sensitivity and the Pipelle had $86 \%$ sensitivity, when correlated with the final diagnosis (Del Priore et al. 2001). The sensitivity and specificity were $100 \%$ for detecting atypical hyperplasia and carcinoma with Tao Brush in 200 cases in the report of Wu et al. (2000). Williams et al. found that adequate samples were significantly more likely to be obtained using the Tao Brush than the Pipelle among 200 high-risk women. A significantly greater proportion of women preferred the Tao Brush to the Pipelle endometrial sampler (Williams et al. 2008).

However, it was difficult using the Tao Brush to distinguish simple hyperplasia without atypia from disordered proliferative endometrium or to diagnose endometrial polyps, according to $\mathrm{Wu}$ et al. (2000). Insertion of the Tao Brush was unsuccessful in $20 \%$ of nulliparous women and $8 \%$ of parous women, whereas Pipelle was unsuccessful in $22 \%$ of attempts among nulliparous women compared with $8 \%$ of parous women in Williams' research. The 
Table 2 Review of the literature on Tao Brush for diagnosis of endometrial lesions

\begin{tabular}{lllllll}
\hline Year & References & Cases & Tao Brush & $\begin{array}{l}\text { Curettage or } \\
\text { hysterectomy }\end{array}$ & $\begin{array}{l}\text { Specimen } \\
\text { satisfaction (\%) }\end{array}$ & $\begin{array}{l}\text { Pathological } \\
\text { accuracy }(\%)\end{array}$ \\
\hline 1997 & Maksem et al. (1997) & 100 & 100 & 100 & 100 & 96.0 \\
2001 & Del Priore et al. (2001) & 101 & 101 & 101 & - & 95.5 \\
2000 & Wu et al. (2000) & 200 & 200 & 200 & 95.5 & 92.5 \\
2003 & Wu et al. (2003) & 633 & 633 & 156 & 89.9 & 91.0 \\
\hline
\end{tabular}

additional cost of the Tao Brush biopsy compared to the Pipelle biopsy was approximately $£ 100$ (Williams et al. 2008). Also, in theory, the Tao Brush has the disadvantage of not collecting enough endometrial cells of the uterine horns because of its round configuration.

\section{SAP-1 device}

The SAP-1 device (Fig. 2b) was patented and received permission to be used in China in 2001. The sheath of this sampler is approximately $3 \mathrm{~mm}$ in diameter and $25 \mathrm{~cm}$ in length. This protective sheath outside the loop can prevent contamination with cervical and vaginal cells (Wen et al. 2015). To collect endometrial cells, the device is first inserted to the level of the fundus and then the outer sheath pulled back, and then the loop is rotated in a clockwise direction for 15 circles. After collecting enough endometrial cells, the outer sheath is pushed to the tip and the device removed.

The SAP-1 sampler may become a reliable method for screening endometrial carcinoma and its precursors, especially in postmenopausal and asymptomatic women. In the study by Wen et al., adequate specimens for cytology were obtained from 1458/1541 patients (96.3\%) using the SAP-1 sampler. The accuracy of endometrial cytology for diagnosing endometrial carcinoma and its precursors was $92.4 \%$ (sensitivity, $73 \%$; specificity, $95.8 \%$; positive predictive value, $75 \%$; and negative predictive value, $95.3 \%$ ) (Wen et al. 2015). However, there have not been enough clinical trials to date supporting the feasibility of the SAP-1 device. Like the Tao Brush, in theory, the SAP-1 device also will not adequately collect cells in the uterine horn.

Other samplers such as the Uterobrush (Fujihara et al. 2006; Iavazzo et al. 2011), Medscand Endorette (Moberger et al. 1998), Cytospat (Antoni et al. 1997), Endopap (Van den Bosch et al. 1996), Tis-U-Trap (Koonings et al. 1990a, b; Frishman and Jacobs 1990), Honest Uterine Brush (Yanoh et al. 2014) have also been used in the clinic, but reports detailing their use appear less often in the literature.

\section{Li brush}

Due to the limitations of the samplers described above, our team invented a new endometrial sampler, named the Li Brush (Fig. 2c), which received a patent in 2014 (ZL.201420720356.8). Compared with other samplers, the Li Brush was designed as an inverted cone, similar in shape to the uterine cavity. In theory, this Brush can collect more endometrial cells than possible with other samplers, especially cells in the uterine horns (Fig. 2), allowing a more accurate diagnosis of endometrial lesions. Clinical trials of the Li Brush have been launched in outpatient and inpatient clinics in the Department of Gynecology of the First Affiliated Hospital, Xi'an Jiaotong University (XJTU1AHCR 2014-007).

\section{Conclusions and future challenges}

All of the devices described herein for evaluating endometrial changes have some disadvantages or limitations for clinical use. It appears that in clinical trials the Tao Brush provides more accurate diagnoses, specimen satisfaction, and pathological accuracy for detecting endometrial lesions. However, sampling insufficiency and costs remain problems that need to be solved for effective screening of endometrial lesions. The devices being developed for endometrial screening should possess the following characteristics. First of all, the screening tool should collect as much endometrial specimen as possible for evaluation and diagnosis, especially cells in the uterine horns. Second, the endometrial specimen should accurately reflect the condition of the uterine cavity to more accurately guide clinical intervention and treatment. Furthermore, the screening tool should be cost-effective in order to be used in a wide range of women for early detection of endometrial lesions, with the goal of improving the prognosis of endometrial carcinoma. Thus, additional efforts should be undertaken to develop an endometrial screening device that could provide more complete histological and cytological information about the uterine cavity, which could be widely used by the female population.

Acknowledgments This research was supported by the Clinical Research Award of the First Affiliated Hospital of Xi' an Jiaotong University, China (XJTU1AH2014-007); by a grant from the International Cooperation Project of Shaanxi Province (2013kw-30-04); by a grant from the National Natural Science Foundation of China 
(81472823); and by the Fundamental Research Funds for Xi'an Jiaotong University (xjj2015093). We thank Mrs Boning Wu in Luoshang Decorate Limited Company who helped us to draw the figures in this review.

\section{Compliance with ethical standards}

Conflict of interest The authors declare no conflicts of interest.

Open Access This article is distributed under the terms of the Creative Commons Attribution 4.0 International License (http://creativecommons.org/licenses/by/4.0/), which permits unrestricted use, distribution, and reproduction in any medium, provided you give appropriate credit to the original author(s) and the source, provide a link to the Creative Commons license, and indicate if changes were made.

\section{References}

Abdelazim IA, Aboelezz A, Abdulkareem AF (2013) Pipelle endometrial sampling versus conventional dilatation \& curettage in patients with abnormal uterine bleeding. J Turk Ger Gynecol Assoc 14(1):1-5

Antoni J, Folch E, Costa J, Foradada CM, Cayuela E, Combalia N, Rue M (1997) Comparison of cytospat and pipelle endometrial biopsy instruments. Eur J Obstet Gynecol Reprod Biol 72(1):57-61

Batool T, Reginald PW, Hughes JH (1994) Outpatient Pipelle endometrial biopsy in the investigation of postmenopausal bleeding. Br J Obstet Gynaecol 101(6):545-546

Ben-baruch G, Seidman DS, Schiff E, Moran O, Menczer J (1994) Outpatient endometrial sampling with the Pipelle curette. Gynecol Obstet Investig 37(4):260-262

Bistoletti P, Hjerpe A (1993) Routine use of endometrial cytology in clinical-practice. Acta Cytol 37(6):867-870

Bray F, Loos AH, Oostindier M, Weiderpass E (2005) Geographic and temporal variations in cancer of the corpus uteri: incidence and mortality in pre- and postmenopausal women in Europe. Int $\mathrm{J}$ Cancer J Int du Cancer 117(1):123-131

Broso P (1995) Cervico-vaginal and endometrial cytology in the screening for endometrial cancer. Minerva Ginecol 47(11):503-507

Bunyavejchevin S, Triratanachat S, Kankeow K, Limpaphayom KK (2001) Pipelle versus fractional curettage for the endometrial sampling in postmenopausal women. $\mathrm{J}$ Med Assoc Thail $=$ Chotmaihet thangphaet 84(Suppl 1):S326-S330

Check JH, Chase JS, Nowroozi K, Wu CH, Chern R (1989) Clinical evaluation of the Pipelle endometrial suction curette for timed endometrial biopsies. J Reprod Med 34(3):218-220

Del Priore G, Williams R, Harbatkin CB, Wan LS, Mittal K, Yang GC (2001) Endometrial brush biopsy for the diagnosis of endometrial cancer. J Reprod Med 46(5):439-443

Demirkiran F, Yavuz E, Erenel H, Bese T, Arvas M, Sanioglu C (2012) Which is the best technique for endometrial sampling? Aspiration (pipelle) versus dilatation and curettage (D\&C). Arch Gynecol Obstet 286(5):1277-1282

Dijkhuizen FPHLJ, Mol BWJ, Brolmann HAM, Heintz APM (2000) The accuracy of endometrial sampling in the diagnosis of patients with endometrial carcinoma and hyperplasia - a metaanalysis. Cancer 89(8): 1765-1772

Eddowes HA, Read MD, Codling BW (1990a) Pipelle: a more acceptable technique for outpatient endometrial biopsy. Br J Obstet Gynaecol 97(10):961-962
Eddowes HA, Read MD, Codling BW (1990b) Pipelle-a more acceptable technique for outpatient endometrial biopsy. Brit J Obstet Gynaecol 97(10):961-962

Elsandabesee D, Greenwood P (2005) The performance of Pipelle endometrial sampling in a dedicated postmenopausal bleeding clinic. J Obstet Gynaecol 25(1):32-34

Fakhar S, Saeed G, Khan AH, Alam AY (2008) Validity of Pipelle endometrial sampling in patients with abnormal uterine bleeding. Annals of Saudi Med 28(3):188-191

Foster-Rosales A, Koontz SL, de Perez OM, Leon K (2003) Cost savings of manual vacuum aspiration for endometrial sampling in $\mathrm{El}$ Salvador. Contraception 68(5):353-357

Frishman G, Jacobs S (1990) A randomized clinical-trial comparing Pipelle and Tis-u-trap for endometrial biopsy. Obstet Gynecol 76(2):315-316

Fujihara A, Norimatsu Y, Kobayashi TK, Iwanari O, Nagaoka S (2006) Direct intrauterine sampling with Uterobrush: cell preparation by the "flicked" method. Diagn Cytopathol 34(7):486-490

Gao J, Yang G, Wen W, Cai QY, Zheng W, Shu XO, Xiang YB (2015) Impact of known risk factors on endometrial cancer burden in Chinese women. Eur J Cancer Prev 25(4):329-334. doi:10.1097/ CEJ.0000000000000178

Goldberg GL, Tsalacopoulos G, Davey DA (1982) A comparison of endometrial sampling with the Accurette and Vabra aspirator and uterine curettage. S Afr Med J 61(4):114-116

Guido RS, Kanbour-Shakir A, Rulin MC, Christopherson WA (1995) Pipelle endometrial sampling. Sensitivity in the detection of endometrial cancer. J Reprod Med 40(8):553-555

Gungorduk K, Asicioglu O, Ertas IE, Ozdemir IA, Ulker MM, Yildirim G, Ataser G, Sanci M (2014) Comparison of the histopathological diagnoses of preoperative dilatation and curettage and Pipelle biopsy. Eur J Gynaecol Oncol 35(5):539-543

Hemalatha AN, Pai MR, Raghuveer CV (2006) Endometrial aspiration cytology in dysfunctional uterine bleeding. Indian J Pathol Microbiol 49(2):214-217

Iavazzo C, Vorgias G, Mastorakos G, Stefanatou G, Panoussi A, Alexiadou A, Plyta S, Lekka C, Kalinoglou N, Dertimas V et al (2011) Uterobrush method in the detection of endometrial pathology. Anticancer Res 31(10):3469-3474

Kaunitz AM, Masciello A, Ostrowski M, Rovira EZ (1988) Comparison of endometrial biopsy with the endometrial Pipelle and vabra aspirator. J Reprod Med 33(5):427-431

Kaur N, Chahal JS, Bandlish U, Kaul R, Mardi K, Kaur H (2014) Correlation between cytological and histopathological examination of the endometrium in abnormal uterine bleeding. J Cytol 31(3):144-148

Kawana K, Yamada M, Jimbo H, Shirai T, Takahashi M, Sano Y, Shiromizu K (2005) Diagnostic usefulness of endometrial aspiration cytology for endometrial cancer cases with normal curettage findings. Acta Cytol 49(5):507-512

Kazandi M, Okmen F, Ergenoglu AM, Yeniel AO, Zeybek B, Zekioglu O, Ozdemir N (2012) Comparison of the success of histopathological diagnosis with dilatation-curettage and Pipelle endometrial sampling. J Obstet Gynaecol 32(8):790-794

Kim MK, Seong SJ, Lee TS, Ki KD, Lim MC, Kim YH, Kim K, Joo WD (2015) Comparison of diagnostic accuracy between endometrial curettage and pipelle aspiration biopsy in patients treated with progestin for endometrial hyperplasia: a Korean Gynecologic Oncology Group Study (KGOG 2019). Jpn J Clin Oncol 45(10):980-982

Kipp BR, Medeiros F, Campion MB, Distad TJ, Peterson LM, Keeney GL, Halling KC, Clayton AC (2008) Direct uterine sampling with the Tao brush sampler using a liquid-based preparation method for the detection of endometrial cancer and atypical hyperplasia: a feasibility study. Cancer 114(4):228-235 
Kitiyodom S (2015) The adequacy of endometrial sampling: comparison between manual vacuum aspiration and metal curettage method. J Med Assoc Thail =Chotmaihet thangphaet 98(6):523-527

Koonings PP, Moyer DL, Grimes DA (1990a) A randomized clinicaltrial comparing Pipelle and tis-u-trap for endometrial biopsyreply. Obstet Gynecol 76(2):316

Koonings PP, Moyer DL, Grimes DA (1990b) A randomized clinicaltrial comparing Pipelle and tis-u-trap for endometrial biopsy. Obstet Gynecol 75(2):293-295

Kriseman MM (1982) Description of a new disposable uterine sampler (the Accurette) for endometrial cytology and histology. S Afr Med J 61(4):107-108

Leclair CM, Zia JK, Doom CM, Morgan TK, Edelman AB (2011) Pain experienced using two different methods of endometrial biopsy: a randomized controlled trial. Obstet Gynecol 117(3):636-641

Leng X, Wang M, Zhang SL, Wang D, Cao W, Yang XH (2013) Different methods for the diagnosis of endometrial histological comparative study. Zhonghua fu chan ke za zhi 48(12):891-895

Leonardi M, Provenzale P, Zanardini L, Bellicini G (1993) The role of the Vabra aspirator in the screening of endometrial carcinoma. Our experience. Minerva Ginecol 45(9):395-398

Longacre TA, Chung MH, Jensen DN, Hendrickson MR (1995) Proposed criteria for the diagnosis of well-differentiated endometrial carcinoma. A diagnostic test for myoinvasion. Am J Surg Pathol 19(4):371-406

Lubbers JA (1977) Diagnostic suction curettage without anesthesia an investigation into practical usefulness of vabra aspirator. Acta Obstet Gynecol Scand 62:1-12

Machado F, Moreno J, Carazo M, Leon J, Fiol G, Serna R (2003) Accuracy of endometrial biopsy with the Cornier pipelle for diagnosis of endometrial cancer and atypical hyperplasia. Eur $\mathrm{J}$ Gynaecol Oncol 24(3-4):279-281

Maksem J, Sager F, Bender R (1997) Endometrial collection and interpretation using the Tao brush and the CytoRich fixative system: a feasibility study. Diagn Cytopathol 17(5):339-346

Masukawa T (1981) Endometrial aspiration cytology in the diagnosis of hyperplasia and carcinoma. Acta Cytol 25(1):48

Moberger B, Nilsson S, Palmstierna S, Redvall L, Sternby N (1998) A multicenter study comparing two endometrial sampling devices-Medscand Endorette TM and Pipelle de Cornier R. Acta Obstet Gynecol Scand 77(7):764-769

Morse AR, Ellice RM, Anderson MC, Beard RW (1982) Reliability of endometrial aspiration cytology in the assessment of endometrial status. Obstet Gynecol 59(4):513-518

Naim NM, Mahdy ZA, Ahmad S, Razi ZR (2007) The Vabra aspirator versus the Pipelle device for outpatient endometrial sampling. Aust N Z J Obstet Gynaecol 47(2):132-136

Niklasson O, Johansson R, Stormby N (1981) Screening of endometrial carcinoma by jet wash and endo-uterine aspiration cytology. Acta Obstet Gynecol Scand 60(2):125-129

Polson DW, Morse A, Beard RW (1984) An alternative to the diagnostic dilatation and curettage-endometrial cytology. Br Med J 288(6422):981-983

Poppendiek G, Bayer KH (1981) The cytology of endometrium by aspiration - a method for the early detection of endometrial carcinoma. Geburtsh Frauenheilk 41(3):188-191

Rauf R, Shaheen A, Sadia S, Waqar F, Zafar S, Sultana S, Waseem S (2014) Outpatient endometrial biopsy with Pipelle versus diagnostic dilatation and curettage. J Ayub Med Coll Abbottabad 26(2):145-148

Roberts M, Rodgers AD, Johri S, Case BD (1994) Endometrial cytology-evaluation of samples obtained by outpatient aspiration. Brit J Obstet Gynaecol 101(7):628-629
Rodriguez GC, Yaqub N, King ME (1993) A comparison of the Pipelle device and the Vabra aspirator as measured by endometrial denudation in hysterectomy specimens: the Pipelle device samples significantly less of the endometrial surface than the Vabra aspirator. Am J Obstet Gynecol 168(1 Pt 1):55-59

Rosler EM, Wilken H, Beust M (1991a) Aspiration cytology-endometrial diagnosis in women with perimenopausal and postmenopausal bleedings. Zentralblatt Gynakol 113(19):1025-1032

Rosler EM, Wilken H, Beust M (1991b) Aspiration cytology-endometrium diagnosis of peri- and postmenopausal bleeding disorders. Zentralblatt Gynakol 113(19):1025-1032

Sanam M, Majid MM (2015) Comparison the diagnostic value of dilatation and curettage versus endometrial biopsy by Pipelle-a clinical trial. Asian Pac J Cancer Prev 16(12):4971-4975

Siegel R, Naishadham D, Jemal A (2013) Cancer statistics, 2013. CA Cancer J Clin 63(1):11-30

Siegel R, Ma JM, Zou ZH, Jemal A (2014) Cancer Statistics, 2014. Ca-Cancer J Clin 64(1):9-29

Sierecki AR, Gudipudi DK, Montemarano N, Del Priore G (2008) Comparison of endometrial aspiration biopsy techniques specimen adequacy. J Reprod Med 53(10):760-764

Smith K, Snyder RN, Willie S, Cove KJ (1980) Direct endometrial aspiration cytology—evaluation. Acta Cytol 24(1):75

Sundsbak HP, Jebsen P (1994) The Pipelle. A good instrument for histological endometrial diagnosis. Tidsskrift for den Norske laegeforening: tidsskrift for praktisk medicin, ny raekke 114(3):317-318

Tabata T, Yamawaki T, Ida M, Nishimura K, Nose Y, Yabana T (2001) Clinical value of dilatation and curettage for abnormal uterine bleeding. Arch Gynecol Obstet 264(4):174-176

Tajima M, Inamura M, Nakamura M, Sudo Y, Yamagishi K (1998) The accuracy of endometrial cytology in the diagnosis of endometrial adenocarcinoma. Cytopathology 9(6):369-380

Tanriverdi HA, Barut A, Gun BD, Kaya E (2004) Is pipelle biopsy really adequate for diagnosing endometrial disease? Med Sci Monit 10(6):Cr271-Cr274

Tao LC (1997) Direct intrauterine sampling: the IUMC Endometrial Sampler. Diagn Cytopathol 17(2):153-159

Tripathy SN, Mahanty J (1990) Place of aspiration cytology in dysfunctional uterine bleeding. J Indian Med Assoc 88(9):247-248

Van den Bosch T, Vandendael A, Wranz PA, Lombard CJ (1996) Endopap-versus Pipelle-sampling in the diagnosis of postmenopausal endometrial disease. Eur J Obstet Gynecol Reprod Biol 64(1):91-94

van Hoeven KH, Zaman SS, Deger RB, Artymyshyn RL (1996) Efficacy of the Endo-pap sampler in detecting endometrial lesions. Acta Cytol 40(5):900-906

Vuopala S, Klemi PJ, Maenpaa J, Salmi T, Makarainen L (1989) Endobrush sampling for endometrial cancer. Acta Obstet Gynecol Scand 68(4):345-350

Wen J, Chen R, Zhao J, Dong Y, Yang X, Liao QP (2015) Combining endometrium sampling device and SurePath preparation to screen for endometrial carcinoma: a validation study. Chin Med J 128(5):648-653

Williams AR, Brechin S, Porter AJ, Warner P, Critchley HO (2008) Factors affecting adequacy of Pipelle and Tao Brush endometrial sampling. BJOG 115(8):1028-1036

Wu HH, Harshbarger KE, Berner HW, Elsheikh TM (2000) Endometrial brush biopsy (Tao brush). Histologic diagnosis of 200 cases with complementary cytology: an accurate sampling technique for the detection of endometrial abnormalities. Am J Clin Pathol 114(3):412-418

Wu HHJ, Casto BD, Elsheikh TM (2003) Endometrial brush biopsyan accurate outpatient method of detecting endometrial malignancy. J Reprod Med 48(1):41-45 
Yang GCH, Wan LS (2000) Endometrial biopsy using the Tao Brush (R) method-a study of 50 women in a general gynecologic practice. J Reprod Med 45(2):109-114

Yanoh K, Norimatsu Y, Munakata S, Yamamoto T, Nakamura Y, Murata T, Kobayashi TK, Hirai Y (2014) Evaluation of endometrial cytology prepared with the Becton Dickinson SurePath method: a pilot study by the Osaki Study Group. Acta Cytol 58(2):153-161
Youssif SNM, Mcmillan DL (1995) Outpatient endometrial biopsythe Pipelle. Brit J Hosp Med 54(5):198-201

Zorlu CG, Cobanoglu O, Isik AZ, Kutluay L, Kuscu E (1994) Accuracy of pipelle endometrial sampling in endometrial carcinoma. Gynecol Obstet Investig 38(4):272-275 